\title{
Patient-reported Symptom Burden, Rate of Completion of Palliative Radiotherapy and 30-day Mortality in Two Groups of Cancer Patients Managed With or Without Additional Care by a Multidisciplinary Palliative Care Team
}

\author{
CARSTEN NIEDER $^{1,2}$, ASTRID DALHAUG $^{1,2}$, ELLINOR HAUKLAND $^{1,2}$ and KIRSTEN ENGLJÄHRINGER ${ }^{1}$ \\ ${ }^{1}$ Department of Oncology and Palliative Medicine, Nordland Hospital, Bod $\phi$, Norway; \\ ${ }^{2}$ Department of Clinical Medicine, Faculty of Health Sciences, \\ UiT - The Arctic University of Norway, Troms $\phi$, Norway
}

\begin{abstract}
Background/Aim: The aim of this study was to analyze differences in symptom burden, baseline and outcome parameters, including completion of palliative radiotherapy and 30-day mortality, between patients treated with palliative radiotherapy $(R T)$ who were managed exclusively by regular oncology staff or a multidisciplinary palliative care team (MPCT) in addition. Patients and Methods: This was a retrospective single-institution analysis. Comparison of two groups of patients: MPCT versus none ( $n=36$ and 65 , respectively). All patients provided Edmonton symptom assessment system (ESAS) data before RT. Results: The MPCT group included significantly more patients with reduced performance status. Furthermore, these patients had higher ESAS symptom scores, except for two items (dyspnea, sleep). The largest differences were observed for pain, fatigue, anxiety and depression. The significant difference in pain scores was also reflected in different opioid medication rates. Failure to complete radiotherapy was more common in the MPCT group (11 and 2\%, respectively, $p=0.05)$. Thirty-day mortality was different, too (28 and $2 \%$, respectively, $p=0.0001)$. The Kaplan-Meier survival curves were not significantly different (1-year survival rates 21 and 25\%, respectively, $p=0.27)$. Conclusion: The MPCT group was characterized by a higher symptom burden. Prognostic factors such as performance status were not balanced between the two groups. Despite this fact, actuarial overall
\end{abstract}

Correspondence to: Dr. Carsten Nieder, Department of Oncology and Palliative Medicine, Nordland Hospital, 8092 Bod $\varnothing$, Norway. Tel: +47 75578449, Fax: +47 75534975, e-mail: carsten.nieder@nlsh.no

Key Words: Palliative radiotherapy, Edmonton symptom assessment system, palliative care team, supportive care. survival was comparable. Given the high rate of 30-day mortality in the MPCT group, efforts to optimize criteria for initiation of radiotherapy are warranted.

Patients referred for palliative radiotherapy experience a variety of symptoms such as pain, reduced mobility, dyspnea or nausea, which also differ in severity $(1,2)$. These symptoms can be captured with different tools and questionnaires, e.g., the Edmonton symptom assessment system (ESAS) (3-5). Given that radiotherapy often results in gradual improvement that tends to peak several days or even weeks after completed treatment, rapid interventions might be needed in addition, e.g., different types of medication (6). In this context, additional expertise from different health care professions might improve the overall benefit in terms of rapid symptom control and better quality of life (QoL). Multidisciplinary palliative care teams (MPCT) are able to contribute to better symptom management and improved care pathways (7-10). A randomized trial of early palliative care, limited to patients with newly diagnosed metastatic non-small cell lung cancer (NSCLC) and not tied to radiotherapy utilization, elucidated the impact of such approaches $(11,12)$. Participants $(\mathrm{n}=151)$ were recruited at a single institution during the time period between 2006 and 2009. Early palliative care integrated with standard oncology care was compared to standard oncology care alone. Patients assigned to the experimental study arm consulted with a member of the MPCT within 3 weeks of enrollment and at least monthly thereafter. If assigned to the standard care arm, the patients only met with the MPCT on request. Early palliative care integrated with standard oncologic care led to significant improvements in QoL and mood from baseline to 12 weeks. Fewer patients received aggressive end-of-life care, yet median survival was longer among patients receiving early palliative care (11.6 versus 8.9 months). 
In our clinical practice, referral to the hospital's MPCT was not standardized. Thus, some patients scheduled to receive palliative radiotherapy were managed by regular oncology staff, while others also had contact with the MPCT at that point in time. The purpose of the present study was to identify disparities in MPCT utilization and differences in baseline symptom burden and outcome parameters (completion of radiotherapy, 30-day mortality, overall survival) between the two groups.

\section{Patients and Methods}

We performed a retrospective analysis of a database in which all patients treated with palliative radiotherapy at our hospital are registered. In order to be able to analyze baseline symptom burden, we only included patients who started their treatment in the time period after our standard work-up had been modified to also include ESAS assessment (since 2012). In order to assess long-term survival with sufficient follow-up time, patients treated after 2015 were not included. The target volumes included distant metastases, lymph node metastases or primary tumors. Due to their different biological behavior, hematological malignancies and primary central nervous system tumors were excluded. Stereotactic radiotherapy was not available. Typical fractionation regimens were $3 \mathrm{~Gy} \times 10,4 \mathrm{~Gy} \times 5$ or $8 \mathrm{~Gy} \times 1$. We used the hospital's electronic patient record (EPR) system to determine whether standard oncology care or additional care by the MPCT was provided. Typically, the MPCT was already involved before referral to radiotherapy, but we also included patients with simultaneous start of radiotherapy planning and MPCT care. ESAS data were collected at the time of nurse and physician consultation immediately before imaging for treatment planning.

Referral to the MPCT was not standardized. Rather, individual decisions were made by the treating clinical oncologists responsible for chemo- and radiotherapy delivery, based on symptom severity, pain control or need for initiation of home care services, taking into account patient preferences. Regular weekly meetings between clinical oncologists and the MPCT took place. All patients were covered by the national public insurance system. Therefore, no outof-pocket costs were incurred for any patient, regardless of management approach/treatment intensity. In other words, no particular socioeconomic barriers prevented patients from access to the MPCT.

Radiation treatment details and date of death were available from the EPR system. Survival time was measured from the start of radiotherapy. Actuarial survival curves were generated by KaplanMeier method and compared by log-rank test [IBM SPSS Statistics 24 (IBM Corporation, Armonk, NY, USA)]. Sixteen patients were alive at the time of analysis (censored observations at last clinical contact). Date of death was entered in all other patients. Univariate analyses of baseline parameters consisted of two-sided Pearson chisquare and Fisher's exact probability test (statistical significance defined as $p \leq 0.05$ ).

\section{Results}

Of the 101 patients with available baseline ESAS data, 36 (36\%) received additional care by the MPCT. Overall, 17 patients $(17 \%)$ were irradiated early after their cancer
Table I. Patients characteristics. Univariate analysis of baseline parameters for patients treated with palliative RT with or without care by a multidisciplinary palliative care team (MPCT).

\begin{tabular}{|c|c|c|c|}
\hline Parameter & $\begin{array}{c}\text { Number of } \\
\text { patients } \\
\text { without MPCT }\end{array}$ & $\begin{array}{l}\text { Number of } \\
\text { patients } \\
\text { with MPCT }\end{array}$ & $p$-Value \\
\hline Patient number & 65 & 36 & \\
\hline ECOG performance status & & & 0.003 \\
\hline $0 / 1$ & 31 & 6 & \\
\hline 2 & 22 & 12 & \\
\hline $3 / 4$ & 12 & 18 & \\
\hline Mean age at RT (years, range) & $72,51-89$ & $69,49-91$ & 0.13 \\
\hline Gender & & & 0.64 \\
\hline Male & 49 & 25 & \\
\hline Female & 16 & 11 & \\
\hline Family status ${ }^{a}$ & & & 0.07 \\
\hline Single & 22 & 6 & \\
\hline Married or partner & 42 & 30 & \\
\hline Primary tumor site & & & 0.62 \\
\hline Prostate & 21 & 10 & \\
\hline Breast & 6 & 6 & \\
\hline Lung (small cell) & 1 & 0 & \\
\hline Lung (non-small cell) & 18 & 8 & \\
\hline Bladder & 5 & 0 & \\
\hline Colorectal & 4 & 1 & \\
\hline Others & 10 & 11 & \\
\hline Irradiated target volumes ${ }^{b}$ & & & 0.44 \\
\hline Bone metastases & 40 & 25 & \\
\hline Brain metastases & 8 & 4 & \\
\hline Lung tumors & 8 & 2 & \\
\hline Lymph nodes, soft tissue, skin & 7 & 3 & \\
\hline Others & 9 & 4 & \\
\hline Prescribed number of fractions & & & 0.81 \\
\hline $1-4$ & 5 & 5 & \\
\hline $5-9$ & 18 & 11 & \\
\hline 10 & 27 & 14 & \\
\hline $11-15$ & 13 & 6 & \\
\hline$>15$ & 2 & 0 & \\
\hline Disease extent & & & 0.56 \\
\hline Distant metastases & 56 & 32 & \\
\hline No distant metastases & 9 & 4 & \\
\hline Liver metastases & & & 0.56 \\
\hline No & 54 & 32 & \\
\hline Yes & 11 & 4 & \\
\hline Progressive non-irradiated disease & & & 0.15 \\
\hline No & 38 & 15 & \\
\hline Yes & 27 & 21 & \\
\hline Steroids during RT & & & 1.0 \\
\hline No & 27 & 15 & \\
\hline Yes & 38 & 21 & \\
\hline Analgesics & & & 0.0001 \\
\hline No opioids & 35 & 2 & \\
\hline Opioids (oral, transdermal) & 30 & 25 & \\
\hline Opioids (pump) & 0 & 9 & \\
\hline Systemic cancer treatment & & & 0.84 \\
\hline No & 30 & 18 & \\
\hline Started before RT & 35 & 18 & \\
\hline
\end{tabular}

ECOG: Eastern cooperative oncology group; RT: radiotherapy. aunknown in one case; ${ }^{b_{\text {some }}}$ patients had more than one type of target irradiated. 
Table II. Edmonton symptom assessment system data (mean, standard deviation).

\begin{tabular}{lccc}
\hline Parameter & Without MPCT & With MPCT & $p$-Value \\
\hline Pain (when not moving) & $2.4,2.6$ & $3.7,2.5$ & 0.017 \\
Pain (when moving) & $3.4,2.9$ & $6.2,2.9$ & 0.0001 \\
Fatigue & $3.7,3.0$ & $5.6,2.4$ & 0.001 \\
Nausea & $1.0,1.8$ & $1.5,2.1$ & 0.18 \\
Dyspnea & $2.7,2.8$ & $2.5,2.8$ & 0.74 \\
Dry mouth & $2.6,2.9$ & $3.6,2.6$ & 0.09 \\
Appetite & $3.4,3.2$ & $4.7,3.3$ & 0.05 \\
Anxiety & $2.0,2.5$ & $3.7,3.6$ & 0.008 \\
Depression & $1.5,2.1$ & $3.3,3.4$ & 0.002 \\
Constipation & $2.2,3.0$ & $3.3,3.3$ & 0.1 \\
Sleep & $2.6,2.8$ & $2.5,2.8$ & 0.89 \\
Overall wellbeing & $3.3,2.6$ & $4.2,2.3$ & 0.08 \\
\hline
\end{tabular}

Maximum symptom severity $=10$ on a scale from $0-10$. MPCT: Multidisciplinary palliative care team.

diagnosis (within 3 months, an arbitrary definition). Three of these $(18 \%)$ received additional care by the MPCT. The mean time from diagnosis to radiotherapy was similar in the groups with and without MPCT care (58 and 51 months, respectively), $p=0.51$. The characteristics of the two groups are shown in Table I. A significant difference existed regarding poor performance status, which was more common in the MPCT group. A trend $(p=0.07)$ was observed regarding family status. Forty-two percent of married or partnered patients received MPCT care, compared to $21 \%$ of single patients.

As shown in Table II, the MPCT group had higher ESAS symptom scores, except for two items (dyspnea, sleep). The largest differences were observed for pain, fatigue, anxiety and depression. The difference in pain scores was also reflected in different opioid medication rates (Table I). Failure to complete radiotherapy was higher in the MPCT group (11 and $2 \%$, respectively, $p=0.05)$. Thirty-day mortality was different, too (28 and $2 \%$, respectively, $p=0.0001$ ). Median survival was not significantly different, 4.2 months with MPCT and 6 months without MPCT. The 1-year survival rates were 21 and $25 \%$, respectively, $p=0.27$ (Figure 1).

\section{Discussion}

This study was designed as an expansion of our previous work (13), because we now had the opportunity to include patient-reported ESAS data. The purpose was to identify disparities in MPCT utilization (age, gender etc.) and differences in baseline symptom burden and outcome parameters (completion of radiotherapy, 30-day mortality, overall survival) between the two groups. Only $17 \%$ of the patients were irradiated within 3 months after their cancer diagnosis. The other patients were treated relatively late
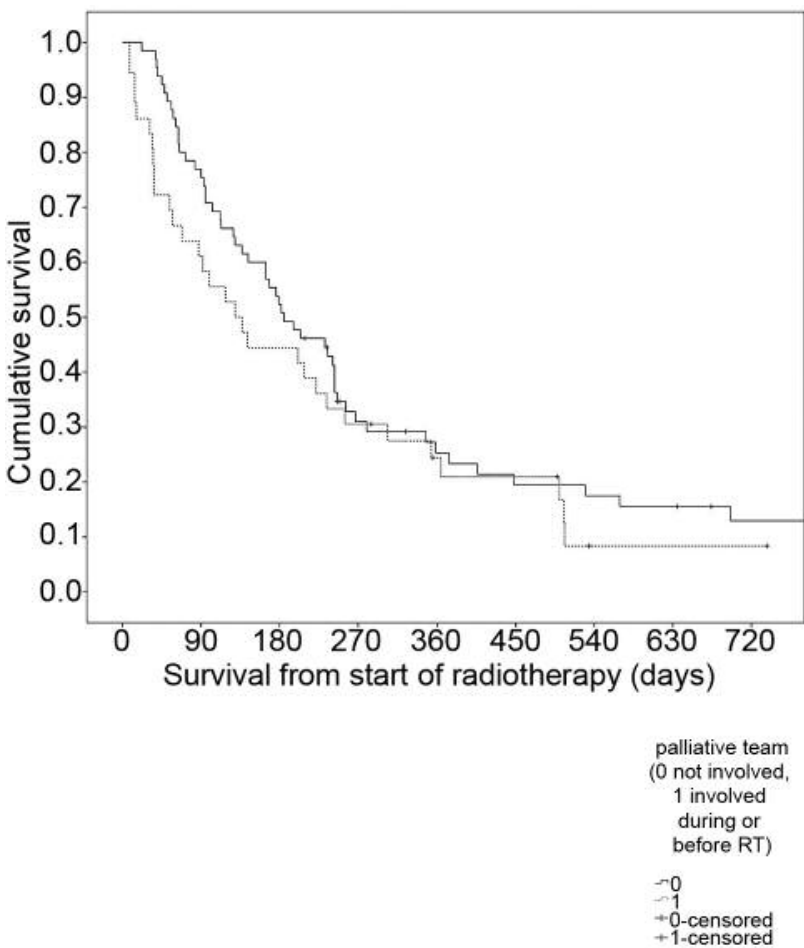

Figure 1. Actuarial overall survival (Kaplan-Meier estimate). Median 4.2 months in the group managed by MPCT and 6.0 months in the group managed with standard care, $p=0.27$.

during the disease trajectory. Many patients (64\% overall) had bone metastases. Prostate and lung cancer were common primary tumors. Statistically significant disparities were not identified, however single patients had lower MPCT utilization rates compared to married or partnered patients.

Apparently, the MPCT was involved mainly in the care of patients with larger symptom burden, as reflected in the significantly different ESAS scores. Especially the pain scores were significantly higher (mean $3.7 v s .2 .4$ and $6.2 \mathrm{vs}$. 3.4 (not moving/moving), respectively. Given the higher pain scores, it is logical that more patients in the MPCT group used opioid medications. All patients who were prescribed continuous opioids via pumps were in the MPCT group. The presence of higher pain scores is also expected to result in impaired activities of daily living and lower performance scores. Only $17 \%$ of the MPCT patients had a performance status of 0 or 1 . We and others have previously shown that certain ESAS items influence prognosis, even if one corrects for confounders such as performance status in multivariate analyses (14-16). Given that our MPCT cohort had worse ESAS scores and performance status, it is no surprise that the 30-day mortality was higher in the MPCT group (28 vs. $2 \%$ ). From our point of view, the proportion of patients 
irradiated during the last month of life, i.e. during terminal illness, was too high in the MPCT group. Much lower rates were found in previous analyses of patients who received palliative radiotherapy in any setting and at any point during the disease trajectory (17-20), e.g., 12\% in a large UK study of almost 15,000 treatments (21). Propagating the 30-day mortality data as useful endpoint relies on the assumption that radiotherapy during terminal illness is unable to improve symptoms and/or quality of life and only provides burdensome disadvantages and increased costs. A disadvantage of our study is that it did not include followup ESAS data. Therefore, we cannot confirm the hypothesis that radiotherapy during the last month of life in general fails to provide symptom improvement.

We are currently studying predictive models that may help reduce initiation of radiotherapy during the last month of life (or 30-day mortality) (22) and other groups are also developing prognostic scores (23-25). It is probably equally important not to deny access to radiotherapy if a clinically meaningful improvement of symptoms can be expected. The present study revealed that failure to complete radiotherapy was uncommon, however the risk was higher in the MPCT group (11 and 2\%, respectively). Previous analyses showed that radiotherapy withdrawal often resulted from disease progression (26). A German multicenter study reported unscheduled termination of radiotherapy in $12 \%$ of patients, without stratification for MPCT care (27). It is not straightforward that 30-day mortality was significantly different, while the Kaplan-Meier curves showed similar median and 1-year survival rates for the two groups in our study. Probably, the MPCT group consisted of patients with vastly different prognosis. Assuming that early palliative care improves survival (11), this effect may explain to some degree why the survival curves did not separate more after the initial demise of patients with terminal disease, especially in the light of the large bias towards poor performance status in the MPCT group. It is also important to note that performance status may improve after successful palliative interventions.

As mentioned before, referral to and timing of MPCT care were not standardized at our institution. Rather, individual assessment was performed, which might have been subjective. Trigger points for automatic referral may solve this problem in the future (28). Further drawbacks of our study include that statistical power was limited and that longitudinal ESAS data were not assessed. More sophisticated tools than the ESAS were not part of standard clinical care during the time period of this study.

\section{Conclusion}

An increasing amount of data suggests that MPCTs play an important role in the multidisciplinary management of patients with incurable cancer. In our clinical setting, the
MPCT group was characterized by higher symptom burden (ESAS scores). Prognostic factors such as performance status were not balanced between the two groups. Despite this fact, actuarial overall survival was comparable. Given the high rate of 30-day mortality in the MPCT group, efforts to optimize criteria for initiation of radiotherapy are warranted.

\section{Conflicts of Interest}

The Authors declare that they have no competing interests.

\section{References}

1 van Oorschot B, Rades D, Schulze W, Beckmann G and Feyer P: Palliative radiotherapy - new approaches. Semin Oncol 38: 443-449, 2011.

2 Lutz ST, Jones J and Chow E: Role of radiation therapy in palliative care of the patient with cancer. J Clin Oncol 32: 29132919, 2014.

3 Caissie A, Culleton S, Nguyen J, Zhang L, Zeng L, Holden L, Dennis K, Chan E, Jon F, Tsao M, Danjoux C, Sahgal A, Barnes E, Koo K and Chow E: EORTC QLQ-C15-PAL quality of life scores in patients with advanced cancer referred for palliative radiotherapy. Support Care Cancer 20: 841-848, 2012.

4 Ganesh V, Zhang L, Chan S, Wan BA, Drost L, Tsao M, Danjoux C, Barnes E, McDonald R, Rowbottom L, Zaki P, Chow R, Hwang MK, DeAngelis C, Lao N and Chow E: An update in symptom clusters using the Edmonton Symptom Assessment System in a palliative radiotherapy clinic. Support Care Cancer 25: 3321-3327, 2017.

5 Hui D and Bruera E: The Edmonton Symptom Assessment System 25 years later: Past, present, and future developments. J Pain Symptom Manage 53: 630-643, 2017.

6 Pituskin E, Fairchild A, Dutka J, Gagnon L, Driga A, Tachynski P, Borschneck JA and Ghosh S: Multidisciplinary team contributions within a dedicated outpatient palliative radiotherapy clinic: a prospective descriptive study. Int J Radiat Oncol Biol Phys 78: 527-532, 2010.

7 Nieder C, Tollåli T, Haukland E, Reigstad A, Flatøy LR and Engljähringer K: Impact of early palliative interventions on the outcomes of care for patients with non-small cell lung cancer. Support Care Cancer 24: 4385-4391, 2016.

8 Delgado-Guay MO, Rodriguez-Nunez A, Shin SH, Chisholm G, Williams J, Frisbee-Hume S and Bruera E: Characteristics and outcomes of patients with advanced cancer evaluated by a palliative care team at an emergency center. A retrospective study. Support Care Cancer 24: 2287-2295, 2016.

9 Vayne-Bossert P, Richard E, Good P, Sullivan K and Hardy JR: Integration of oncology and palliative care: setting a benchmark. Support Care Cancer, 2017. doi: 10.1007/s00520-017-3736-2. [Epub ahead of print]

10 Hui $\mathrm{D}$ and Bruera E: Integrating palliative care into the trajectory of cancer care. Nat Rev Clin Oncol 13: 159-171, 2016.

11 Temel JS, Greer JA, Muzikansky A, Gallagher ER, Admane S, Jackson VA, Dahlin CM, Blinderman CD, Jacobsen J, Pirl WF, Billings JA and Lynch TJ: Early palliative care for patients with metastatic non-small cell lung cancer. N Engl J Med 363: 733742, 2010. 
12 Greer JA, Pirl WF, Jackson VA, Muzikansky A, Lennes IT, Heist RS, Gallagher ER and Temel JS: Effect of early palliative care on chemotherapy use and end-of-life care in patients with metastatic non-small cell lung cancer. J Clin Oncol 30: 394-400, 2012.

13 Nieder C, Dalhaug A, Pawinski A, Haukland E, Mannsåker B and Engljähringer K: Palliative radiotherapy with or without additional care by a multidisciplinary palliative care team in patients with newly diagnosed cancer: a retrospective matched pairs comparison. Radiat Oncol 10: 61, 2015.

14 Nieder C, Kämpe TA, Pawinski A and Dalhaug A: Patientreported symptoms before palliative radiotherapy predict survival differences. Strahlenther Onkol, 2018. doi: 10.1007/s00066-0181259-5. [Epub ahead of print]

15 Chow E, Abdolell M, Panzarella T, Harris K, Bezjak A, Warde P and Tannock I: Validation of a predictive model for survival in metastatic cancer patients attending an outpatient palliative radiotherapy clinic. Int J Radiat Oncol Biol Phys 73: 280-287, 2009.

16 Zeng L, Zhang L, Culleton S, Jon F, Holden L, Kwong J, Khan L, Tsao M, Danjoux C, Sahgal A, Barnes E and Chow E: Edmonton symptom assessment scale as a prognosticative indicator in patients with advanced cancer. J Palliat Med 14: 337-342, 2011.

17 Murphy JD, Nelson LM, Chang DT, Mell LK and Le QT: Patterns of care in palliative radiotherapy: A population-based study. J Oncol Pract 9: e220-227, 2013.

18 Guadagnolo BA, Liao KP, Elting L, Giordano S, Buchholz TA and Shih YC: Use of radiation therapy in the last 30 days of life among a large population-based cohort of elderly patients in the United States. J Clin Oncol 31: 80-87, 2013.

19 Kapadia NS, Mamet R, Zornosa C, Niland JC, D'Amico TA and Hayman JA: Radiation therapy at the end of life in patients with incurable non-small cell lung cancer. Cancer 118: 4339-4345, 2012.

20 Jones JA, Lutz ST, Chow E and Johnstone PA: Palliative radiotherapy at the end of life: a critical review. CA Cancer $\mathrm{J}$ Clin 64: 296-310, 2014.

21 Spencer K, Morris E, Dugdale E, Newsham A, SebagMontefiore D, Turner R, Hall G and Crellin A: 30-day mortality in adult palliative radiotherapy - A retrospective population based study of 14,972 treatment episodes. Radiother Oncol 115: 264-271, 2015.
22 Nieder C, Angelo K, Dalhaug A, Pawinski A, Haukland E and Norum J: Palliative radiotherapy during the last month of life: Predictability for referring physicians and radiation oncologists. Oncol Lett 10: 3043-3049, 2015.

23 Janssen S, Van Oorschot B, Käsmann L, Schild SE and Rades D: Validation of a score developed to estimate the 6-month survival of patients treated with palliative local radiotherapy for advanced lung cancer. Anticancer Res 37: 2537-2540, 2017.

24 Rades D, Manig L, Janssen S and Schild SE: A survival score for patients assigned to palliative radiotherapy for metastatic bladder cancer. Anticancer Res 37: 1481-1484, 2017.

25 Rades D, Bolm L, Schild SE and Bartscht T: Survival following palliative external-beam radiotherapy of locally advanced and metastatic liver cancer. Anticancer Res 37: 203-206, 2017.

26 Arenas M, Sabater S, Gascón M, Henríquez I, Bueno MJ, Rius À, Rovirosa À, Gómez D, Lafuerza A, Biete A and Colomer J: Quality assurance in radiotherapy: analysis of the causes of not starting or early radiotherapy withdrawal. Radiat Oncol 9: 260, 2014.

27 van Oorschot B, Schuler M, Simon A, Schleicher U and Geinitz $\mathrm{H}$ : Patterns of care and course of symptoms in palliative radiotherapy: a multicenter pilot study analysis. Strahlenther Onkol 187: 461-466, 2011.

28 Hui D, Mori M, Meng YC, Watanabe SM, Caraceni A, Strasser F, Saarto T, Cherny N, Glare P, Kaasa S and Bruera E: Automatic referral to standardize palliative care access: an international Delphi survey. Support Care Cancer 26: 175-180, 2018.
Received February 11, 2018

Revised February 25, 2018

Accepted February 26, 2018 